\title{
Morality, Imagination and Human decision making
}

L H Human, J Liebenberg \& J C Müller

(Universiteit van Pretoria)

\section{ABSTRACT}

\section{Morality, imagination and human decision making}

The authors of this article explore the possibility of using imagination instead of so-called objective truths in human decision making. They argue that imagination plays a role even if one operates with the objectivist view of morality. What now is needed is to elaborate on the role that imagination plays when humans have to make moral decisions, especially when they experience that they are lost, that they are in a state of aporia. In the approach suggested, one is forced to come to grips with the full complexity of one's situation. No easy, ultimately correct decision is presupposed. Instead, one is forced to take full responsibility both for the construction of alternative stories (and therefore alternative moralities) and also for choosing the preferred story and its desired and undesired moral consequences.

\section{AGAINST ETHICS}

A few years ago, John Caputo (1993:1) wrote:

I have for sometime now entertained certain opinions that I have been reluctant to make public. But I have, at length concluded that the time has come to air my views, clearly and without apology, and to suffer whatever consequences come my way. I am against ethics. Here I stand. I cannot do otherwise.

Of course he does so as the fashion of the past decade or so dictates - by donning a not too inconspicuous deconstructionist cloak. We believe he does not take such a deconstructionist stance merely because it is fashionable, but perhaps because he is aware of the extreme failure of objectivist ethics to help people live lives that are both morally responsible and fulfilling in terms of their own humanity. Because, unlike the church and our own moral upbringing try to tell us, living morally is not always merely a matter of having proper ethics, of making the right choice. In that sense there is a "fundamental" reason (if we may use this metaphor) for taking such a critical stance towards ethics as it is popularly understood, also in this country. For Caputo (1993:4) the 
obvious choice against ethics proves to be a deconstructionist approach, because

(d)econstruction takes as its subject matter the task of making one's way along an aporia, along an almost impassable road, where the ground may at any moment shift beneath our feet. Deconstruction issues a warning that the road ahead is still under construction, that there is blasting and the danger of falling rock. Ethics, on the other hand, hands out maps which lead us to believe that the road is finished and there are superhighways all along the way.

The metaphor of the "way" that Caputo is talking about here is of course the way out of a specific moral dilemma; the way out of the moral quagmire of indecision; the way to clarity, decision and finality; the way to moral and ethical bliss. It is of course the way that objectivist ethics promises. Except - it appears that we are becoming increasingly aware that there is no such moral bliss possible, there is no final moral answer, and there is no one last ethical judgement that will enable one to at last sleep peacefully.

Now, because neither of the present authors is a philosopher or an ethicist, we cannot talk about morality and ethics with the same degree of competence as does Caputo or any other moral philosopher, and perhaps we are looking for trouble in writing about imagination, morality and human decision making in the first place. It is for this reason that we wish to make it clear that we do not think that what we are about to say is necessarily new or philosophically profound.

In fact, we would have liked to say at this point - "Here we stand" in such a dramatic fashion as Caputo when he is echoing Luther - except that we have a slight problem. We are not quite sure where we stand, or if we stand at all. It is not that we experience ourselves as drifting, or falling, or floating. It is much more a case of not being quite sure whether there is a map with which to specify our location, that is, of us being part of a labyrinth, or a maze or a web. We can, to some extent, explain how we got here; we can explain our own struggles with objectivist ethics, or we can explain our engagement with each other's stories, or with those of other people. We can explain our delight with narrative and metaphor and hairy things with unclear boundaries such as post-modernism, deconstruction and the like. But the problem comes in when we try to get some distance from our present (unspecified) location. Because, as soon as we lift off, we discover that we are part of a web of endless links, most of which we are not aware of and many others we have forgotten about. And to make matters worse - the web is without boundaries so that our very attempt at finding out where we are has exactly the oppo- 
site result. Our attempt to draw a map indicating our position results in yet another maze without a centre or boundaries. Enough of that. Let us start then at the beginning, with the truth.

\section{KNOWLEDGE AND TRUTH}

If we are to believe the historians of philosophy, there was a time when life was simple, the truth was true and revelation was unproblematic. If we are to believe contemporary philosophers, things are no longer that simple. In fact most of us know from our own experience that the truth is not what it used to be. We know that the popular aphorism: "The more things change the more they stay the same" is not quite true as far as "the truth" is concerned.

Scholars (Smith 1993; Edgar 1995; Ozment 1995; Barker 1996; Euben 1997) divide the history of Western civilisation into three distinct time periods - the pre-modern, modern and post-modern.

In the pre-modern era knowledge or "truth" was seen as something that was revealed to people by God through religious scriptures and revelation. Mcloyd (1997) states that during the modern era the focus shifted from a religious to a scientific framework. The dominant epistemology during the modernist time period derives from Newtonian physics that assumed that there is an objective reality waiting to be discovered via reason, science and scientific method.

In the post-modern era knowledge and "truth" are not seen as phenomena that are revealed, either through religious scriptures nor discovered via reason, science and scientific methods, but rather as being constructed - socially constructed - between people within a specific context. Gosden (1995) states that the emphasis in the post-modern time period is not on knowledge as a product, but on knowledge as a process between people. Gergen (1995) describes post-modernism as humanism developing from individual to relational humanism. In the post-modern era language is used not to access objective reality, but to construct reality (Anderson \& Goolishian 1988). It is no longer possible to "tell the truth" in isolation, instead, "telling the truth" has become a dialogical process involving history, culture, humans and the divine.

\section{MORALITY AND STORY}

Perhaps the most dominant metaphor of humanity in Pre-modern western society was that of man (sic!) as image of God. Ethics in this era was dominated by the injunction: Be holy for I am holy! The Modern era, dominated by positivism, saw the rise of psychology as one of the primary sources of knowledge about humans.

One metaphor that prevailed within psychology and the other helping professions in this era were, for example, "man (sic) as machine", 
which implied that people had to be fixed by experts. Another metaphor is one that we would like to call the "onion metaphor". Helping professionals working with this metaphor seek the "core" of people's personality by peeling off layer by layer until the true self is revealed. Recently the narrative and social constructionist metaphors came to the fore (Monk et al 1997). Within the narrative and/or social constructionist metaphor it is important to understand that people construct their personal life stories within cultural stories.

Using the narrative metaphor leads us to think about people's lives as stories and to work with them to experience their life stories in ways that are meaningful and fulfilling. Using the metaphor of social construction leads us to consider the ways in which every person's social, interpersonal reality has been constructed through interaction with other human beings and human institutions and to focus on the influence of social realities on the meaning of peoples' lives (Freedman \& Combs 1996:1).

In every society, there are dominant cultural stories and less domi-nant or alternative cultural stories. In our culture heterosexuality is the dominant cultural story regarding human sexuality and homosexuality as well as lesbianism are less dominant stories or alternative stories regarding human sexuality. But this view is not restricted to popular culture only. For example, homosexuality and lesbianism were still seen as psychopathology in the Diagnostic and Statistical Manual III (DSMIII) of the American Psychological Association (APA) in the early nineteen eighties. The underlying assumption was that heterosexuality was right and homosexuality and lesbianism were wrong. Stated in a slightly different way heterosexuality was the desired way for emotional and sexual intimacy and homosexuality and lesbianism were the less desired ways for emotional and sexual intimacy between human beings.

People internalise the dominant cultural stories and these stories become their personal stories. Couples can internalise the story that "the man is the head of the house" and by so doing designate hierarchical roles for the male and female within the marriage. Parents can internalise the story that "children must be seen and not heard" as their personal story of relating to their children. Within many congregations the minister is seen as "the spokesperson of God who represents the truth". They therefore listen to the Sunday sermon with the expectation that the minister has the answer to their problems. They often do not attempt to find their personal answer to their own problematic life stories. For many years psychiatrists and psychologists were seen (are still seen?) as "experts regarding human behaviour and their clients seen as patients". 
By internalising this cultural story regarding psychiatrists and psychologists the so-called patients are kept in a disempowered position regarding their own lives while psychiatrists and psychologists maintain the power within the mental health field.

But what happens when people no longer internalise the dominant cultural stories as their personal life stories, but instead choose to engage in dialogue with these stories as is happening more and more in our society? What happens when someone, trying to write her/his authentic personal life story, comes into conflict with the dominant cultural stories (based on universal, objective, normative, timeless and a-historical "truths"). It results in a classic double bind, as often happens with moral dilemmas such as euthanasia, abortion, divorce, etc. It is then that people experience severe conflict between the cultural stories on the one hand and their own personal life stories on the other. This moral dilemma puts a person in a state of aporia, as some philosophers of morality like to call it.

\section{STATE OF APORIA}

We know the concept of aporia primarily from Plato's dialogue The Meno. Here Socrates sets out to teach a youth a lesson in geometry. The boy is enticed to guess the area of a square and is led step by step to realise that he was mistaken. He eventually arrives at a moment of embarrassment, a moment of not knowing, a moment where he has to realise that he does not know, which is the moment of aporia. Literally he does not know the way forward - he is without a way.

As far as morality and ethics are concerned, the idea of aporia relates to the metaphor of life as a journey. Within this metaphor, it follows that such an aporia happens whenever one no longer has sense a of moral direction. It happens every time someone has a difficult moral decision to make and there is no clear and definite way out. Yet within the objectivist ethical model this should not be so. The correct or proper moral thing to do should be clear, or if it is not clear, at least clarity should be found by just becoming familiar with the applicable rule. "Objectivism claims that there are absolute moral laws, that they can be discovered by reason, and that they can be applied directly and objectively to real situations" (Johnson 1993:4). So, within the objectivist tradition aporia, the experience of being lost, of not knowing where to go next, is simply a matter of not knowing the rules, or perhaps lacking the skill to apply the relevant rule to the particular situation in which one finds oneself. We will return to this a little later.

But first we want to look at another metaphoric understanding of aporia - one not related to life as a journey - but to life as part of a web of interactions. In a very interesting article Nicholas C Burbules (1997) writes about the sense of being lost which often overtakes one when 
searching for information on the World Wide Web. One link after another is followed, initially with some sense of direction until there comes a point where one click is one link too many. Suddenly it is not quite clear how a particular link or result has any relevance for what one has initially set out to do. He describes this feeling of lostness as an aporia. "When I have lost my way, I have two problems: one is not knowing how I got here; the other is not knowing where to go next" (Burbules 1997:2). Those of us who have at one time or another searched on the World Wide Web will be familiar with this feeling of being lost on the Web. In this metaphor, aporia is still related to a journey, but no longer a journey on a path, but a kind of intellectual journey along links on the Internet. In this metaphor, matters are far more complex and complicated than on a road or some geographical area, which is why it is designated as a $W e b$. In this respect, Burbules refers to Deleuze and Guattari who describe two methods of organising information, two kinds of root systems. The one is a centrally organised hierarchical system. It is structured along lines of importance, branching off into structures of diminishing significance. On the other hand one gets the rhizomatic system, a system that spreads into all directions with no centre, no given hierarchy of importance (Burbules 1997:3).

If one considers the event of aporia to be the moment of "not knowing, of indecision", from these two perspectives it becomes clear that the hierarchical way of ordering information is at home within the objectivist paradigm, where things happen along fixed lines, depending on importance and significance relative to some unchanging truth. In many forms of moral objectivism, this truth must be adhered to and protected at all costs. There is no room for any kind of personal input (imagination) in trying to find solutions to moral dilemmas. They are simply treated as logical problems that need to be solved.

However, what would happen if one chooses to address the problem of aporia, of "having no way out" of "being lost" within a rhizomatic framework, one that "grows in all directions, allows passage along many alternate routes, with no governing set of rules" (Burbules 1997:3) and where there is no hierarchy.

The first thing that would happen is that there would be no search for an ultimate answer, no attempt at finding the absolute solution, no looking for moral gurus or other agents of ultimate truth. This will have immediate consequences for how one views such a state of "not knowing". Aporia would no longer be a state to avoid at all costs; it would no longer be seen as a place to get out of as soon as possible. It would no longer be seen, as was the case with the student in the Meno as something to be embarrassed about. No longer would there be an attempt to find answers outside oneself, outside of the situation in some universal, a-historic truth dimension which has very little to do with the contin- 
gency of human life, and which all too often leads to a failure to take responsibility for one's own life and decisions. In one sense, of course, it would render redundant all prophets, preachers, ethicists and other agents of morality, since they will no longer be asked to mediate revelation or knowledge or whatever else they purport to be bestowing on their followers. On the other hand, there would be a very real need for such individuals because people simply do not know how to live without absolutes, they do not know how to live the life of uncertainty, which is why people believe that the way to curb relativism is by improving the rules. People will need people who can teach them to live the dangerous life of living as morally responsible (even religious) human beings, in a world with no absolutes.

But why should one talk about dismissing absolutes when so many people seem quite content to live with absolutes? For us two reasons are pertinent. First, more and more people are finding that objectivist ethics is inadequate for solving their everyday moral dilemmas. It is simply too rigid and constricting to cope with the rich tapestry of everyday living. Secondly since our (South African) re-admission to the international arena, civil society can no longer ignore the fact that there are different worldviews and cultures laying equal claim in possessing the(a) truth. As long as our society was authoritarian (especially white, Afrikaner South Africa), organised along strict hierarchical structures, it was possible for the church and other moral watchdogs to control people's behaviour by enforcing rigid ethical rules. In such an environment people hardly dared to question the dominant cultural and religious discourses. With the opening up of South African society and the consequent exposure to the global village, which is in essence non-hierarchical, there has been a growing discontent with all forms of authoritarian power structures, including those that claim revelation and/or science as ultimate sources of power and truth.

As always, when one talks about dismissing absolutes, the immediate reaction is that one has become an anarchist or a relativist, or some other very dubious and morally questionable creature by taking this stance. However, to save ourselves from such a label, we have decided to seek refuge in second-generation cognitive science. We do this, not only because we think this provides a quite credible way out of the impasse that results from the either/or of absolutism and relativism, but also especially because it addresses the fallacy that humans can make "truly rational" decisions which are based on "pure" logic. In this respect we would like to refer to Mark Johnson's Moral Imagination and his views regarding morality, reason and imagination. In taking this position, we are quite aware that we are opting for a position which has its own objectivist commitments. 
These commitments are echoed in the words of Johnson (1993:1), when he remarks:

Recent empirical research in the cognitive sciences has revealed that both our concepts and our reasoning about them are grounded in the nature of our bodily experience and are structured by various kinds of imaginative processes. Consequently, since moral reasoning makes use of these same general cognitive capacities, it, too, is grounded in embodied structures of meaning and is imaginative through and through.

According to this view, there is no such thing as purely rational decisionmaking, simply because imagination forms part of all kinds of human conceptualisation. Therefore, it does not matter that one believes one is making rational decisions in terms of some or other absolute moral principle. The mere fact that one is comparing, that one is considering the relation between one's own situation, and some general rule, or as is most often the case, a specific exception to a very general rule, implies that one is using one's imagination.

However, this does not really address the fundamental problems we have with the objectivist position. There is a Moral Law Folk Theory (Johnson 1993:13-31), which governs the absolutist understanding of human reason and decision-making and which links up with the folk theory of what humans are and how they function. Most of us are quite familiar with this folk theoretical understanding of humans. According to this view, humans as moral agents are rational animals who have a dual nature, a bodily part and a mental part. The bodily part is closely related to us being animals and it accounts for our basest desires and actions. Fortunately, according to this folk theory of humans, we also have a mental part; we have reason and it is because of this that we differ from animals in being moral entities. We need not be captive to our bodily desires but we have a choice, and as long as we choose the correct course of action we will act morally correct. As Johnson (1993:127) puts it: "... the problem of morality stems from the fact that our animal desire is not intrinsically rational. Will must be strong to resist the force of desire, whenever desire or passion goes against what reason demands".

The problem with this understanding of humans as bifurcated creatures is that it does not allow us to understand ourselves as essentially embodied beings. There is no war waging between body and mind, simply because our brains are embodied entities. The view of a war waging between body and mind/soul is a result of a particular philosophical understanding of what it means to be human, but one which has 
very little resemblance to what we have learned over the last few decades about the way in which human minds work. We cannot divest ourselves from our embodiment. Furthermore this dualistic understanding of humans "defines moral personhood without reference to the social relations and cultural roles that form such a large part of our personal identity. And it has no place for imagination in its account of moral reasoning" (Johnson 1993:124-125).

The Moral Law Folk Theory and the Objectivist Folk Model of the self, open the door to an a-historic understanding of both morality and of human beings as moral agents. In this view, the fact that human beings live their lives as historical beings is merely accidental and of no consequence whatsoever for the moral dilemmas which confront one in everyday living. Being moral implies that one becomes familiar with the correct principle for any given situation, and applies this timeless truth to that situation in the proper manner. But as Johnson (1993:11) remarks:

There is abundant empirical evidence that narrative is a fundamental mode of understanding, by means of which we make sense of all forms of human action. There are various types of narrative structure that play a role in how we understand actions, evaluate moral character, and project possible solutions to morally problematic situations. Narrative is not just an explanatory device, but is actually constitutive of the way we experience things. No moral theory can be adequate if it does not take into account the narrative character of our experience.

Within the objectivist view of human beings they are seen as free, "moral agents who can choose which, if any contextual features it will allow to influence its deliberations. Thus the moral agent purports to choose freely what aspects of its physical, social and cultural environment it will permit to have an effect on its actions" (Johnson 1993:150). Yet such a view is highly problematic, because we are far more socially constituted, far more historically situated and far more changeable than objectivism allows.

\section{IMAGINATION}

We have remarked already that imagination plays a role even if one operates with the objectivist view of morality. We now need to elaborate on the role that imagination plays when humans have to make moral decisions, especially when they experience that they are lost, that they are in a state of aporia.

From the time that we are little, we use narrative and imagination in giving account of our deeds. When a mother demands an explanation 
from a toddler on why there is honey all over the bathroom mirror, she uses narrative and imagination to explain her behaviour. So she explains the state of the bathroom mirror by telling a story in which it makes perfect sense to use honey as a cleaning agent. The mother's question might presuppose right and wrong, or some logical explanation - but the child refers to narrative instead. Even when she grows older, and buys into the rights and wrongs of society, she will still use narrative to explain her behaviour - as we all do.

Humans use narrative and imagination to make sense of their lives. It is in this regard that Johnson and others suggest that one uses imagination and narrative whenever one has to make a difficult moral or lifechanging decision, in our metaphor, when one experiences aporia. If one views moral deliberation as an imaginative process, and imaginative exploration of the possibilities inherent within any given situation, the decision to be made is not so much a choice between right and wrong, but a playing out of different life scenarios. In this process one has recourse to one's own moral tradition, cultural myths, exemplary heroes, etc. One creates alternative stories, based on the possibilities and impossibilities inherent within one's current situation, and taking into consideration one's past, relationships, dreams, beliefs, etcetera. Note that there is no fixed rule as to which of these must have the biggest influence on one's decision. Instead, the decision is primarily guided by one's perception of which possibility will eventually have the most meaningful ending. This is impossible without using one's imagination, because imagination is the primary means by which we compare, dream, evaluate, construct and tell stories.

Of course we are not saying that this approach will make moral dilemmas disappear overnight. The experience of being lost, of having no way out, is part and parcel of the life of every person who wishes to live a morally responsible life. But at least this approach empower people in a way that is not possible within the objectivist paradigm. It recognises the complexity of human life and decision-making. It does not purport to provide easy, timeless and simple answers for the moral issues that people face every day. Furthermore, it recognises the historical, narrative texture of people's lives. It links up with the natural way in which humans "actually" make decisions daily. What is more, it demands a much greater responsibility from an individual in her or his world. In the objectivist view one only takes the "right" decision, and then lives with the consequences knowing that God, the church or society has actually made the decision for them and they need not really bother themselves too much with the negative consequences of their decision. However, in the approach that we suggest, one is forced to come to grips with the full complexity of one's situation. No easy, ultimately correct decision is presupposed. Instead, one is forced to take full 
responsibility both for the construction of alternative stories (and therefore alternative moralities) and also for choosing the preferred story and its desired and undesired moral consequences.

\section{THE STORY OF GERHARD BRINK AND TRUDIE DEL- PORT $^{1}$}

Gerhard Brink is a 24-year-old white male student at the University of Stellenbosch. He was born and grew up in Belville, South Africa. His family of origin consisted of his father, mother and four children (two brothers and two sisters) - Gerhard being youngest of the four. He had a "typical Afrikaner upbringing". Trudie is from a town in the Northern Cape and of the same upbringing as Gerhard.

Gerhard and Trudie (21) had been in a relationship with each other for three years. The moral dilemma that they had experienced in this relationship was whether or not to get sexually involved with each other. As they are Christians and members of the Dutch Reformed Church they had to make the decision within various cultural stories that have an influence on their personal life stories. They had to take into account the religious story that "sex before marriage is wrong and even sinful", and their peer group story on the other hand. This story held that sex in a premarital relationship was acceptable. Two views dominated the peer group story about sex. On the one hand sex was seen as a "free for all", on the other it was located within a committed relationship.

Gerhard grew up in what he calls a conservative Afrikaans family. His father and mother married young and were therefore sexually active at about Gerhard and Trudie's age. In the family they grew up in they were told that pursuing a professional career was a noble thing to do. It was also very important to attain financial independence before becoming permanently involved with another person. The message they grew up with - and we could say from society at large - was that obtaining a professional qualification and attaining financial security were prerequisites for marriage - which in itself was yet another prerequisite for getting sexually involved with a partner. In trying to resolve this moral dilemma they tried to reconcile the dogma of the church and Afrikaner society at large that "sex before marriage is a sin", with the peer group story regarding sex.

After debating these two apparently irreconcilable stories, they decided that they could only make a decision based on what was important in the here-and-now. Making a decision in the here-and-now also implied taking into account the significant others and Other that were

' In presenting this story, personal details have been altered to protect the persons in question. 
involved in the process of decision-making. The past, present and future of their relationship also had to be taken into account when trying to resolve the moral dilemma - their experience of aporia - that they found themselves in.

In the story of Gerhard and Trudie there are two distinct storylines. The first deals with their description of the moral dilemma in which they find themselves. The universal, objective, normative, timeless and ahistorical "truth" that sex before marriage is not permissible versus their own personal story as a young couple that this so-called "truth" can be questioned and challenged. This constitutes a moral dilemma in their lives. The second storyline deals with the way in which they, as many of their peers, go about trying to resolve the moral dilemma. According to this storyline:

- One makes a decision in the here-and-now.

- The resolution to this particular moral dilemma can only be made with reference to one's relationships (with self, with others and with the Other).

- The time dimension of a relationship (past-present-future; story sequencing) has to be taken into account when trying to resolve moral dilemmas of this nature.

Gerhard and Trudie's story starts out from the objectivist position, which causes them a moral dilemma, "being stuck". They could adhere to the dominant religious story, which denies the story of their own sexuality within a committed relationship. However, they start questioning the authority and relevance of the objectivist position, which informs the dominant religious story regarding pre-marital sex. Instead they opt for a post-objectivist view of morality - one that is quite close to what we have suggested above. They do not solve their experience of aporia, of being lost, of having no way out by applying some objective rule regarding pre-marital sex. Instead, they view themselves imaginatively in the here-and-now as persons involved in various relationships (self, other and the Other). They view all these relationships as part of their history and as contributing to their future, a process in which imagination plays a pertinent role. When they decide together to have pre-marital sex, it is definitely not as an irresponsible couple. Their choice is not primarily one of applying the correct "rule" to the situation. It is rather a highly imaginative process in which they "play out" different scenarios in their minds and take a decision based on how they perceive (again by using his imagination) the ending of each "storyline" to be. In this process they are deliberately taking a stand against certain culturally dominant views and siding with other views, which they find to make more sense. 
In the lives of Gerhard and Trudie there were no easy solution. And it is true that their decision, made within an imaginative process, in the end constitutes a violation of what parents might regard as the more responsible way of dealing with sexuality. However, can we really say that they were morally irresponsible by not just applying an objectivist "truth" to their situation? Was the process they went through in deciding what to do in a state of aporia not a moral process, a process where they had to exhibit guts and take responsibility for their decision? Would the process of decision-making not leave them with a greater sense of being empowered? Would it not enhance them as persons in their own right? And would the same imagination which guided them in this situation, not help them to be a morally responsible people in another situation somewhere in future?

Should we not encourage people to realise that every moral decision is in the end a highly imaginative process? Will it not be more helpful to guide people towards an understanding of ethics and morally responsible living by highlighting the fact that we humans hardly ever make decisions that are guided by reason alone? Perhaps if we do that, we will be able to help people to take the moral principles and guidelines seriously provided by their religious traditions, and which are based on the collective wisdom of many generations of people. Because moral decisionmaking will be understood as an imaginative process, it will of course not mean a slavish adherence to an objectivist truth. Still it will not imply an outright rejection of morality and religious ethics either. And perhaps, if we can do that, we will be able to help people live lives that are both morally responsible, and nevertheless true to their own identities as people living historically determined, contingent lives.

\section{Consulted literature}

Anderson, C L \& Goolishian, H A 1988. Human systems as linguistic systems: Preliminary and evolving ideas about the implications for clinical theory. Family Process 27(4), 371-393.

Atwood, J D 1997. Social construction theory and therapy in Atwood, J D (ed), Challenging family therapy situations: Perspectives in social construction. New York: Springer.

Barker, S 1996. Signs of change: Premodern-modern-postmodern. Albany: State University of New York Press.

Bloland, H G 1995. Post-modernism and higher education. Journal of Higher Education 66(5), 521-559.

Burbules, N C 1997. Aporia, webs, passages, getting lost and learning to go on. Obtained from the Internet, at http://www.ed.uiuc.edu/EPS/PESyearbook/97_docs/burbules.html. Printed by the Philosophy of Education Society.

Caputo, J D 1993. Against ethics. Bloomington: Indiana University Press.

Edgar, W 1995. No news is good news: Modernity, the post-modern, and apologetics. Westminster Theological Journal 57(2), 359-383. 
Euben, R L 1997. Pre-modern, antimodern or post-modern? Islamic and western critiques of modernity. Review of Politics 59(2), 429-459.

Freedman, J \& Combs, G 1996. Narrative therapy: The social construction of preferred realities. New York: Norton.

Gergen, K J 1995. Post-modernism as a humanism. Humanist Psychologist 23, 7182.

Gosden, H 1995. Success in research article writing and revision: A social constructionist perspective. English for Specific Purposes 14(1), 37-57.

Johnson, M 1993. Moral imagination: Implications of cognitive science for ethics. Chicago: University of Chicago Press.

Mcloyd, J 1997. Narrative and psychotherapy. London: Sage.

Monk, G et al 1997. Narrative therapy in practice. San Francisco: Josey-Bass.

Ozment, S 1995. Pre-modern advice for the post-modern young. Public Interest 1119, 54-67.

Smith, D 1993. The pre-modern and the post-modern: Some parallels, with special reference to Hinduism. Religion 23, 157-165.

Vorster, K 1999. Die ontwikkeling van postmoderniteit. (The development of postmodernity). Die Kerkblad: Gereformeerde Kerke in Suid-Afrika 101, 3056, 10 12. 